\title{
Abnormalities of proximal conduction in acute idiopathic polyneuritis: comparison of short latency evoked potentials and F-waves
}

\author{
JC WALSH, C YIANNIKAS, JG MCLEOD \\ From the Department of Neurology, Royal Prince Alfred Hospital, Camperdown, NSW, Australia
}

SUMMARY Motor and sensory conduction studies, F-wave latency, and the latency of evoked potentials from the brachial plexus and cervical spine in response to median nerve stimulation were examined in 17 patients with acute idiopathic polyneuropathy. Short latency evoked potentials provided a higher yield of evidence of abnormalities of proximal conduction than did the F-wave latency. Both methods of studying conduction in the proximal segments of a peripheral nerve may be normal, however, in a small number of patients who have significant pathological lesions.

Acute idiopathic polyneuritis is a common cause of severe generalised paralysis. The peak of disability is reached within 3 to 4 weeks of the onset of symptoms, the subsequent clinical course is that of improvement, and relapses are very rare. ${ }^{1}$ The focal areas of primary demyelination vary in distribution; in some cases pathological changes have been found from the root level to the motor end plate, but in others, most of the demyelination occurred proximally at the root or plexus level. ${ }^{2}$ Similarly, the distribution of pathological lesions in experimental allergic neuritis varies from nerve to nerve. ${ }^{3}$

The asymmetrical distribution of demyelinating lesions in acute idiopathic polyneuropathy is reflected by the asymmetrical impairment in peripheral motor and sensory conduction studies; up to $14 \%$ of patients may have normal peripheral conduction in the presence of diffuse weakness. ${ }^{1}$

The determination of F-wave latency, and of evoked potentials from the brachial plexus and cervical cord in response to median nerve stimulation may provide information about conduction in large myelinated fibres at the plexus and root level in patients with normal peripheral conduction in the upper limbs. There have been reports of prolonged F-wave latency in this disease ${ }^{4-9}$ although marked pathological changes may be present in the motor roots of animals with experimental allergic neuritis that have normal F-wave latencies. ${ }^{3}$

Address for reprint requests: Dr JC Walsh, Dept. of Neurology, Royal Prince Alfred Hospital, Camperdown, NSW 2050, Australia.

Received 15 July 1983 . Accepted 12 September 1983
There have been no detailed studies reported comparing F-wave latency measurements and evoked potentials with peripheral conduction studies. For this reason we report the results of studies performed on 17 patients with acute idiopathic polyneuritis to determine if studies of proximal conduction provide a significant amount of additional information.

\section{Patients and methods}

Seventeen patients were studied who fulfilled the diagnostic criteria.' The mean age was 36.4 years (range, 16-81) and all neurophysiological studies were performed at the one session at a mean interval of 16 days (range, 2-45) after the onset of symptoms.

\section{Peripheral conduction studies}

The nerve conduction study techniques have been described fully elsewhere. ${ }^{10}$ Motor conduction velocities were measured in the median, ulnar and lateral popliteal nerves. Muscle action potentials were recorded with a concentric needle electrode or with surface recording electrodes from the abductor pollicis brevis, abductor digiti minimi and extensor digitorum brevis muscles respectively following supramaximal stimulation of the nerve at two sites, and the conduction velocity was calculated after measuring the latency of the responses from photographic records. Sensory action potentials were recorded with surface electrodes from the median and ulnar nerves at the wrist on stimulating the index and little fingers respectively through ring electrodes. Mixed nerve action potentials were recorded from the lateral popliteal nerve at the neck of the fibula with subcutaneous needle electrodes on stimulating the anterior tibial nerve at the ankle. The latency to peak, and the amplitude of sensory and mixed nerve action potentials were measured from photographic 
records. The stimulus was a square wave of duration 0.2 or $0.5 \mathrm{~ms}$, and amplitude of up to $500 \mathrm{~V}$ derived from a Disa Ministim.

The responses were amplified by a Devices amplifier (type 3160) and displayed on a Medelec M-scope. A time scale derived from a Devices Digitimer and a calibration signal derived from a Devices calibration unit were simultaneously displayed and photographed. The results were compared with control values obtained in this laboratory. ${ }^{10}$

The forearm temperture was measured with a thermistor and ranged from $32 \cdot 4^{\circ} \mathrm{C}$ to $35 \cdot 3^{\circ} \mathrm{C}$.

\section{$F$-wave latency}

The median nerve was stimulated supramaximally at 2 -second intervals just above the wrist with a cathode proximal to the anode. F-waves were recorded with a surface electrode from the abductor pollicis brevis muscle. At least 30 responses were photographed at a gain of $\mathbf{5 0}$ $\mu \mathrm{V} / \mathrm{cm}$ division on a slow-moving photographic paper, and the latency of the earliest F-wave was measured. ${ }^{11}$ The length of the arm was measured from the cervical spine (C7) to the point of stimulation with the arm supinated and abducted to a right angle, and the latencies were compared with those obtained from nine control subjects, plotted against arm length.

\section{Evoked responses}

The median nerve was stimulated at the same site used for F-wave studies and evoked responses were recorded from the brachial plexus and cervical cord with sub-dermal platinum needle electrodes placed at Erb's point and at the second cervical vertebral spine respectively. The "active" electrodes were referred to a common $F_{2}$ electrode. The stimulus was adjusted to produce either a contraction of the abductor pollicis brevis muscle or to be at three times the sensory threshold. The responses were amplified with a Medelec AA6 Mark 3 preamplifier, and Medelec amplifiers which were $3 \mathrm{~dB}$ down at $8 \mathrm{~Hz}$, and $6 \mathrm{~dB}$ down at $3.2 \mathrm{kHz}$; a series of responses were averaged for $30 \mathrm{~ms}$ from the point of stimulation with a Medelec DAV6 averager at a sampling rate of 17 points per ms.

The latencies of the clavicular (N9) and spinal (N13) responses were measured to the negative peak and were compared with those obtained from 11 control subjects, plotted against arm length.

\section{Results}

The results of peripheral nerve conduction studies, F-wave latency and evoked response studies are summarised in the table, and in figs 1 and 2.

There were three patients (cases 1,2,3) in whom the terminal motor latencies or motor conduction velocities were within the demyelinating range; the F-wave latency was prolonged in two of these (cases $1,3)$, and the evoked potentials were abnormal in all three cases.

There were 12 patients (cases 4-14, 17) in whom mild, asymmetrical impairment of motor or sensory conduction was demonstrated. The F-wave latency was prolonged in six patients (cases $4,5,6,10,11$, 14), two of whom had normal evoked potentials. However, abnormal evoked potentials were found in five of the six patients with normal F-wave latency (cases $7,8,9,12,13$ ).

Table Results of nerve conduction studies, F-wave latency and evoked potential latencies from 17 patients with acute idiopathic polyneuritis

\begin{tabular}{|c|c|c|c|c|c|c|c|c|c|c|c|c|c|c|c|c|c|}
\hline \multirow[t]{3}{*}{$P t$} & \multirow{3}{*}{$\begin{array}{l}\text { Sexl } \\
\text { Age } \\
(y r)\end{array}$} & \multicolumn{6}{|c|}{ Motor conduction } & \multicolumn{4}{|c|}{ Sensory action potentials } & \multirow{2}{*}{\multicolumn{2}{|c|}{$\begin{array}{l}\text { Mixed nerve } \\
\text { action potentials } \\
\text { Lateral popliteal } \\
\text { nerve }\end{array}$}} & \multirow{3}{*}{$\begin{array}{l}\text { Arm } \\
\text { length } \\
\text { C7 to } \\
\text { wrist } \\
\\
\mathrm{mm}\end{array}$} & \multirow{3}{*}{$\begin{array}{l}\text { F-wave } \\
\text { Lat } \\
\text { ms }\end{array}$} & \multirow{2}{*}{\multicolumn{2}{|c|}{$\begin{array}{l}\text { Evoked } \\
\text { potentials } \\
\text { N9 }\end{array}$}} \\
\hline & & \multicolumn{2}{|c|}{ Median nerve } & \multicolumn{2}{|c|}{ Ulnar nerve } & \multicolumn{2}{|c|}{$\begin{array}{l}\text { Lateral popliteal } \\
\text { nerve }\end{array}$} & \multicolumn{2}{|c|}{ Median nerve } & \multicolumn{2}{|c|}{ Ulnar nerve } & & & & & & \\
\hline & & $\begin{array}{l}\text { Lat } \\
m s\end{array}$ & $\begin{array}{l}\text { Vel } \\
\mathrm{m} / \mathrm{s}\end{array}$ & $\begin{array}{l}\text { Lat } \\
m s\end{array}$ & $\begin{array}{l}\text { Vel } \\
\mathrm{m} / \mathrm{s}\end{array}$ & $\begin{array}{l}\text { Lat } \\
m s\end{array}$ & $\begin{array}{l}\text { Vel } \\
\mathrm{m} / \mathrm{s}\end{array}$ & $\begin{array}{l}\text { Lat } \\
\text { ms }\end{array}$ & $\operatorname{Amp}_{\mu V}$ & $\begin{array}{l}\text { Lat } \\
m s\end{array}$ & $\underset{\mu V}{A m p}$ & $\begin{array}{l}\text { Lat } \\
m s\end{array}$ & $\underset{\mu V}{A m p}$ & & & $\begin{array}{l}\text { Lat } \\
m s\end{array}$ & $\begin{array}{l}\text { Lat } \\
\text { ms }\end{array}$ \\
\hline 1 & M19 & $12 \cdot 1$ & 47 & $7 \cdot 1$ & 31 & $16 \cdot 8$ & 27 & & 0 & & 0 & & 0 & 670 & $46 \cdot 0$ & $10 \cdot 8$ & $15 \cdot 7$ \\
\hline 2 & $\mathrm{~F} 14$ & $11 \cdot 9$ & 43 & $7 \cdot 1$ & 46 & $21 \cdot 0$ & 38 & & 0 & & 0 & & & 650 & $26 \cdot 5$ & $10 \cdot 0$ & $15 \cdot 0$ \\
\hline 3 & F30 & 17.5 & *- & $6 \cdot 3$ & 34 & $17 \cdot 0$ & 34 & & 0 & & 0 & & 0 & 680 & - & - & - \\
\hline 4 & M23 & 4.0 & 51 & 2.9 & 57 & $8 \cdot 1$ & 39 & $2 \cdot 7$ & 18 & $2 \cdot 3$ & 7 & & 0 & 700 & - & $10 \cdot 1$ & $14 \cdot 0$ \\
\hline 5 & F35 & $5 \cdot 2$ & 50 & $2 \cdot 0$ & 57 & $4 \cdot 0$ & 49 & $4 \cdot 2$ & 4 & 2.5 & 9 & $7 \cdot 0$ & 1 & 700 & 33.0 & $10 \cdot 2$ & $14 \cdot 0$ \\
\hline 6 & F59 & $3 \cdot 2$ & 60 & $2 \cdot 3$ & 60 & $7 \cdot 2$ & 36 & & 0 & & 0 & & 0 & 670 & $28 \cdot 5$ & $10 \cdot 9$ & $14 \cdot 2$ \\
\hline 7 & M81 & $5 \cdot 5$ & 45 & $5 \cdot 2$ & 40 & $7 \cdot 0$ & 50 & & 0 & & 0 & & 0 & 700 & $28 \cdot 0$ & $\begin{array}{l}12 \cdot 0 \\
11 \cdot 8\end{array}$ & \\
\hline $\begin{array}{l}8 \\
9\end{array}$ & $\begin{array}{l}\text { M33 } \\
\text { M18 }\end{array}$ & $\begin{array}{l}3 \cdot 6 \\
3 \cdot 2\end{array}$ & $\begin{array}{l}49 \\
55\end{array}$ & $\begin{array}{l}3 \cdot 0 \\
2 \cdot 8\end{array}$ & $\begin{array}{l}68 \\
57\end{array}$ & $\begin{array}{l}4 \cdot 1 \\
9 \cdot 1\end{array}$ & $\begin{array}{l}51 \\
33\end{array}$ & $\begin{array}{l}3 \cdot 4 \\
4 \cdot 0\end{array}$ & $\begin{array}{l}10 \\
22\end{array}$ & $\begin{array}{l}3 \cdot 8 \\
3 \cdot 6\end{array}$ & $\begin{array}{l}3 \\
8\end{array}$ & & 0 & $\begin{array}{l}720 \\
720\end{array}$ & $\begin{array}{l}29 \cdot 0 \\
31 \cdot 2\end{array}$ & $\begin{array}{l}11 \cdot 8 \\
11 \cdot 3\end{array}$ & $\begin{array}{l}15 \cdot 8 \\
15 \cdot 1\end{array}$ \\
\hline 10 & M61 & $3 \cdot 0$ & 47 & $2 \cdot 3$ & 46 & $5 \cdot 0$ & 51 & 3.4 & 7 & & 0 & & 0 & 740 & 36.5 & - & - \\
\hline 11 & M59 & 3.0 & 49 & 2.7 & 55 & $6 \cdot 2$ & 36 & $3 \cdot 2$ & 9 & $2 \cdot 8$ & 5 & & 0 & 708 & $36 \cdot 0$ & $11 \cdot 1$ & $\overline{10}$ \\
\hline 12 & M52 & 4.0 & 55 & 2.7 & 52 & & - & $2 \cdot 9$ & 10 & $2 \cdot 5$ & 5 & & 0 & 650 & $28 \cdot 0$ & $10 \cdot 2$ & $13 \cdot 0$ \\
\hline 13 & M56 & $4 \cdot 3$ & 48 & $2 \cdot 8$ & 53 & $4 \cdot 0$ & 37 & 3.4 & 2 & $2 \cdot 8$ & 2 & & 0 & 720 & $28 \cdot 0$ & - & - \\
\hline 14 & F21 & $3 \cdot 2$ & 58 & $2 \cdot 0$ & 54 & $5 \cdot 2$ & 53 & $2 \cdot 4$ & 14 & $2 \cdot 1$ & 9 & $6 \cdot 6$ & 1 & 679 & $\bar{z}$ & $10 \cdot 8$ & $13 \cdot 2$ \\
\hline 15 & F25 & 3.7 & 60 & 2.6 & 55 & 6.0 & 55 & 3.4 & 28 & $2 \cdot 8$ & 22 & & & & $25 \cdot 0$ & $9 \cdot 5$ & 13.3 \\
\hline 16 & M16 & 3.0 & 60 & $2 \cdot 4$ & 56 & $4 \cdot 0$ & 55 & $3 \cdot 0$ & 20 & $2 \cdot 8$ & 14 & & & & $27 \cdot 0$ & $10 \cdot 0$ & $13 \cdot 2$ \\
\hline & F16 & 2.6 & 57 & 2. & 61 & $5 \cdot 3$ & 45 & $2 \cdot 8$ & 20 & $2 \cdot 4$ & 14 & $6 \cdot 8$ & 2 & 667 & $24 \cdot 0$ & $9 \cdot 2$ & 12 \\
\hline & range ${ }^{\prime}$ & $2 \cdot 7-5 \cdot 0$ & $48-69$ & $2 \cdot 1-3 \cdot 8$ & $45-68$ & $3.4-7.8$ & $38-57$ & $2 \cdot 2-4 \cdot 0$ & $7-40$ & $2 \cdot 0-3 \cdot 7$ & $5-37$ & $5 \cdot 2-8 \cdot 4$ & $1-15$ & & $24-33$ & $8 \cdot 4-11$ & $12 \cdot 2-1$ \\
\hline
\end{tabular}

* Response not recordable.

†Total range, not corrected for age or arm length; see figs 1 and 2. 


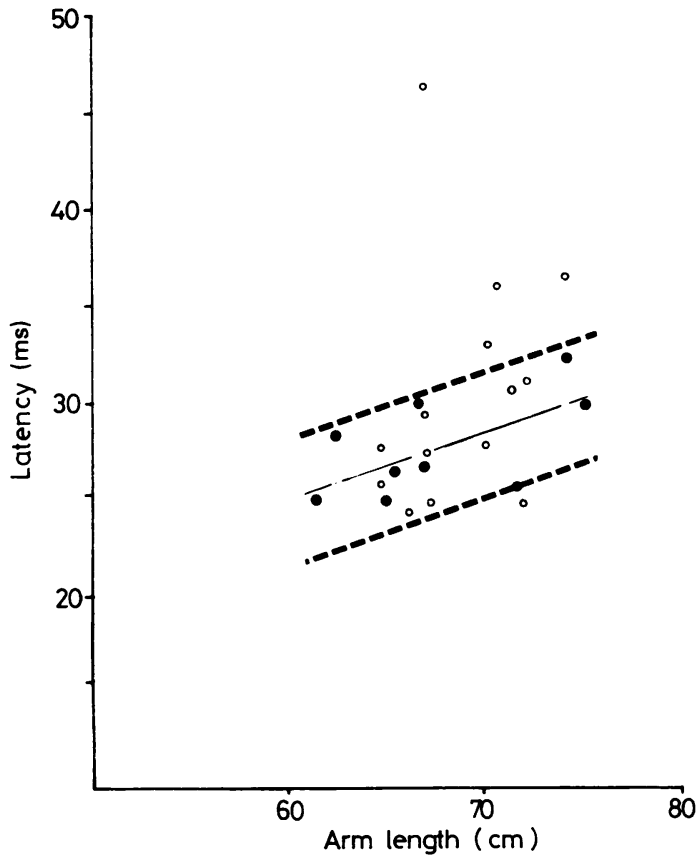

Fig $1 F$-wave latency in control subjects (solid circles) and in subjects with acute idiopathic polyneuritis (open circles). The broken lines indicate the range for control subjects. $A$ response was not recordable from three affected subjects.

There were two patients (cases 15,16 ) in whom peripheral conduction studies were within the control range. Both F-wave latency and evoked potentials were also within the control range.

It is relevant to consider the relationship of peripheral nerve conduction studies in the median nerve alone, with measurements of both F-wave latency and evoked potentials obtained from stimulating that nerve at the wrist.

The F-wave latency was abnormal in eight of the 17 patients studied, and six of these had abnormal conduction peripherally in the median nerve. One of the two patients with normal peripheral conduction had abnormal evoked potentials, so that only one patient had an abnormal F-wave as the sole abnormality detected (case 4).

The F-wave latency was normal in three cases with abnormal peripheral median nerve conduction (cases 2,7,13), and evoked potential abnormalities were present in all three cases.

There were six patients (cases $8,9,12,15,16,17$ ) with normal peripheral median conduction and normal F-wave latency. Evoked potential abnormalities were present in three of these patients (cases 8, 9, 12).

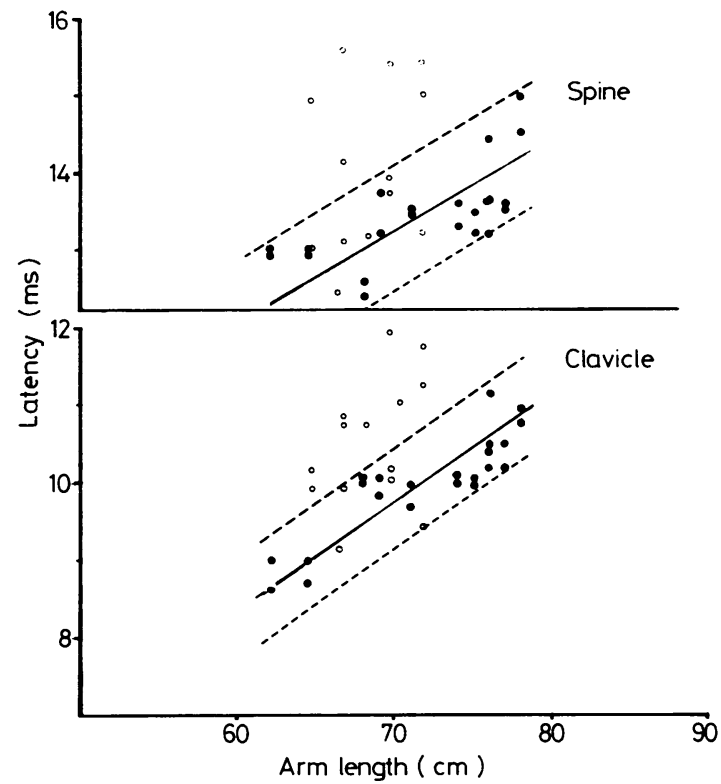

Fig 2 Short latency evoked potential results recorded from the clavicle (N9) and cervical spine (N13) as a result of median nerve stimulation at the wrist. The limits for control subjects (solid circles) are indicated by broken lines; the open circles are responses from affected subjects. Three subjects had absent $N 9$ responses and four had absent $N 13$ responses.

\section{Discussion}

The pathological abnormalities in acute idiopathic polyneuritis may be most marked proximally at the plexus or root level, ${ }^{2}$ and peripheral nerve conduction studies may be normal in some patients. ${ }^{1}$ In the present study peripheral nerve conduction was normal in two of 17 patients examined $(12 \%)$; these patients had the appropriate historical, clinical and spinal fluid features required to establish the diagnosis.

Studies that provide information about conduction through the proximal portion of the peripheral nervous system may provide useful additional information, particularly if there is some uncertainty about the clinical diagnosis.

The $\mathrm{F}$-wave is a response obtained from a muscle as a result of discharge of some anterior horn cells initiated by an antidromic volley artificially produced in their axons. Attempts have been made to assess conduction velocity in the proximal segments of alpha motor neurons by $\mathrm{F}$-wave measurements, and abnormalities have been demonstrated in some patients with acute idiopathic polyneuropathy. ${ }^{458}$ However, it is preferable to consider the more accu- 
rate primary data of minimal latency determination, and to relate these measurements to arm length. ${ }^{6}$ The control values in the present study are similar to those obtained by other workers. " Abnormalities of F-wave latency were demonstated by Lachman and co-workers, ${ }^{8}$ in 10 of 11 patients with acute idiopathic polyneuritis, two of whom had normal peripheral conduction. In the present study the F-wave latency was examined in the median nerve only, to compare the relative yield of abnormalities with that of evoked potential measurements from the brachial plexus and cervical spine, and to compare studies of F-wave latency on one human nerve with previous studies on one nerve in animals ${ }^{3}$ with experimental allergic neuritis.

The F-wave latency was abnormal in eight of the 17 patients $(47 \%)$, but median nerve conduction was abnormal in all but two of these patients, so that F-wave studies detected abnormalities in only $12 \%$ of median nerves with normal peripheral conduction. This may be compared with a similar incidence of $7-14 \%$ in the sciatic nerve of animals with experimental allergic neuritis with normal peripheral conduction. ${ }^{3}$

By contrast, the F-wave latency was normal in three patients with abnormal median nerve conduction. The presence of a normal F-wave latency, however, does not exclude the presence of significant pathological changes in the nerve roots or plexus as it is known from studies on experimental allergic neuritis that the F-wave latency is frequently normal in the presence of ventral root demyelination. ${ }^{3}$

Evoked potentials may be recorded from the brachial plexus and cervical spine as a relatively simple extension of the standard peripheral nerve conduction studies, and in the present studies there were more positive findings with this investigation than with assessment of F-wave latency.

Evoked potential abnormalities were demonstrated in a total of 12 patients $(71 \%)$, six of whom had normal F-wave latencies; and three of whom had normal median nerve conduction as well (cases $8,9,12$ ), illustrating that there is a higher incidence of abnormalities obtained from evoked potential studies. However, there were two patients (cases 4, 5) who had abnormal F-wave latencies and normal evoked potentials.
It is concluded that, in addition to routine motor and sensory nerve conduction studies, useful additonal information about abnormalities of conduction proximally may be obtained by recording evoked potentials from the brachial plexus and cervical spine. Although the yield of abnormalities with this method is higher than assessment of F-wave latency, the latter investigation may be useful in a small number of patients. Both investigations may be within normal limits in a small number of patients who have significant pathological lesions present.

We gratefully acknowledge the support of the Laura Bushell Trust.

\section{References}

${ }^{1}$ McLeod JG, Walsh JC, Prineas JW, Pollard JD. Acute idiopathic polyneuritis. A clinical and electrophysiological follow-up study. J Neurol Sci 1976;27:145-62.

${ }^{2}$ Asbury AK, Arnason BG, Adams RD. The inflammatory lesion in idiopathic polyneuritis. Medicine 1969;48:173-215.

${ }^{3}$ Tuck RR, Antony JH, McLeod JG. F-wave in experimental allergic neuritis. J Neurol Sci 1982;56:173-84.

${ }^{4}$ Kimura J, Butzer JF. F-wave conduction velocity in Guillain-Barre syndrome: assessment of nerve segment between axilla and spinal cord. Arch Neurol 1975;32:524-9.

${ }^{5}$ King D, Ashby P. Conduction velocity in the proximal segments of a motor nerve in the Huillain-Barre syndrome. J Neurol Neurosurg Psychiatry 1976;39:53844.

6 Young RR, Shahani BT. Clinical value and limitations of F-wave determination. Muscle Nerve 1978;1:248-50.

${ }^{7}$ Kimura J. Proximal versus distal slowing of motor nerve conduction velocity in the Guillain-Barre syndrome Ann Neurol 1978;3:344-50.

${ }^{8}$ Lachman T, Shahani BT, Young RR. Late responses as aids to diagnosis in peripheral neuropathy. $J$ Neurol Neurosurg Psychiatry 1980;43:156-62.

9 Shahani BT, Potts F, Dominigue JN. F-response studies in peripheral neuropathies. Neurology (Minneap) 1980;30:409.

${ }^{10}$ Walsh JC, McLeod JG. Alcoholic neuropathy-An electrophysiological and histological study. J Neurol Sci 1970;10:457-69.

11 Wulff $\mathrm{CH}$, Gilliatt RW. F-waves in patients with hand wasting caused by a cervical rib and band. Muscle Nerve 1979;2:452-7. 